\title{
President's Report for the 2006 NACA annual conference
}

\section{OPENING}

The immediate Past President, Dr Gerrit Kornelius, the Vice President, Ms Yvonne Scorgie, members of Council, the NACA Branch Chairpersons and committees, members of NACA, Ladies and Gentlemen.

Two years ago at the AGM in 2004, when I took over the position as President of NACA, I made the comment that 2005 and 2006 would present numerous opportunities, amongst which would be those provided by the challenges of new air quality legislation as well as those of climate change. The challenges have certainly been there. Opportunities have arisen, and it is my contention that NACA has risen to a number of these opportunities.

\section{Strategic workshop}

In February 2004, the NACA Council held a strategic workshop to review and appropriately direct our activities to ensure that NACA's objectives are efficiently progressed. We subsequently re-aligned the NACA Council meetings to optimise our deliberations and ensure that we remain focussed. Over the past year we have continued to reinforce and enhance the focus of Council, and consequently realise the benefits of that 2004 strategic workshop through the progress that has been made in the identified focus areas.

One of these focus areas has been to enhance NACA's activities in the policy and legislation arena, another has been to facilitate capacity building and the sharing of information

\section{Liaison and co-operation with DEAT}

One activity to progress these focus areas has been the fostering of a better relationship between NACA and the Department of Environmental Affairs and Tourism. I think that it is evident from the activities during this week that significant progress has been made. NACA is signing a 3-year Memorandum of Agreement with the Department of Environment and Tourism to coordinate our Annual Conferences with DEAT conferences and workshops. On Monday and Tuesday DEAT held their own Legothla, while yesterday's event provided a platform for the $1^{\text {st }}$ stakeholder workshop on the development of the National Air Quality Management Framework. I am sure that you will agree that the workshop was welcomed by all participants and deemed to be very successful. And today and tomorrow, at our Annual Conference I am pleased to note the participation of the Chief Director: Air Quality and Climate Change and his Directors.

\section{Comment on legislation}

NACA commented extensively on the NEM: AQA when it was been drafted. Similarly we recently provided our input on the standards that were gazetted for public comment in July 2006. Much of our written input has been echoed in Wednesday's workshop. The NACA comments are being posted on our website.

\section{DEAT publications}

Another activity to progress the focus areas has been the peer review of the DEAT series of publications on Air Quality Management. NACA coordinated the peer review of the first three documents, which have subsequently been or are being published. In this regard I must commend Dr Gerrit Kornelius for his role in assembling a team of NACA experts and ensuring that their peer review was performed timeously and efficiently.

In the President Address last year, given on my behalf by the Vice President, Ms Yvonne Scorgie, we mentioned that another potential avenue for providing input into air quality issues is that of the National Environment Advisory Forum (NEAF). This forum was established in 2005 in terms of the National Environmental Management Act, and 
includes members from a variety of backgrounds. I am pleased to say that NACA is one of the organisations that have been invited to engage with NEAF on air quality issues.

\section{Capacity building}

To enhance our interaction with academic institutions, one of the goals set earlier this year by Council was that at least 3 tertiary institutions should participate in the Annual Conference, with appropriate funding from NACA to make this possible. I am pleased to state that this has been achieved - we have students and academics presenting and participating today and tomorrow and I am confident that we will be able to continue this objective into the future, with benefits to improving the skills base in air quality matters in South Africa.

Last year I referred to the new source book for secondary school children on "the air we breathe". I indicated that the editing had taken longer than originally anticipated, so that we were only expecting the book to be published in late 2005/ early 2006. I am pleased to say that the book and associated posters have been published. Our branches are reporting a significant interest in the book, not only from schools but also from organisations purchasing the book from NACA to use in their own interventions with schools.

\section{NACA/ESA "Science to Policy" project}

At last years AGM, we also mentioned the "Science to Policy" project focusing on air quality management in South Africa that is being undertaken jointly with the Environmental Scientific Association. A tight schedule was set with intention to publish the book by end 2006. Unfortunately due to the various commitments that the individuals involved in the project face, it has not been possible to meet the tight schedule. Nevertheless we are engaging with ESA to expedite the work to enable publication in 2007.

The above has been a brief reflection on some of the activities and achievements of NACA over the past year. One key theme that may be inferred from these activities is the partnering that NACA is undertaking with government as well as with other organisations. I was intrigued to note that this was also one of the theme's in this morning's opening address by the MEC Mr Mbulelo Sogoni.

\section{Branch activities}

My thanks, and that of Council go to the Branch committees for their efforts in furthering the objectives of NACA. During the past 12 months there have been very successful seminars and meetings organised by the different branches, in addition to the very successful Annual Conferences that we had in 2005 and this year. As per the standard practice, the Branch Chairpersons will report on their activities later during the AGM.

\section{Administration and Finances}

The Administrator, Roy Stevenson and the Technical Director, Piet Odendaal continued to ably provide their services to NACA. The reports that are expected from NACA as a non-profit organisation were submitted as required. Although it has been easy and quick for me to make this statement, I assure you it required many hours of hard work to achieve this. The Finance Sub-committee of Council regularly met to scrutinise the financial statements to ensure that good governance is being maintained and that fund expenditure progressed the objectives of NACA. I believe that we have considerably strengthened the governance of NACA's financial matters, but will hasten to add that we would like to see it enhanced even further. Council will initiate further improvements as and when appropriate. We will hear during the tabling of the Financial Report that NACA's financial position has improved and that the auditors are satisfied with the financial statements of NACA.

\section{Awards}

Congratulations to those organisations who will receive awards tonight at the GALA Dinner. These awards are well deserved and reflect on the growing awareness of the importance of clean air. Intuitively I believe there are many other individuals and 
organisations whose efforts should be recognised, and I urge members to identify and nominate these individuals and organisations.

\section{Expression of Appreciation}

This has been a busy year, and one in which NACA's stature has increased; for which I must express my appreciation to NACA members for making this possible. The efforts of the President and the Vice President have been supported by the activities of Council members, the Branch Chairpersons and their committees and the permanent staff. I thank the outgoing Council members Jonas Mphepya and Marietha Oosthuizen for their invaluable contribution and welcome incoming Council members. In particular, I would like to thank the immediate Past President, Dr Gerrit Kornelius for his unstinting support and guidance.

After more than 20 years of service to NACA and the NACA Council, our Administrator, Roy Stephenson, has indicated his desire to "retire" from this position in February 2007. In fact, about 6 years ago, Roy expressed this desire, but at the time he was persuaded to continue for an interim period. That interim period stretched to 6 years. On behalf of the NACA members I thank Roy for his services and wish him well in his "retirement".

Our gratitude is also extended to the sponsors of the various seminars and meetings and this Annual Conference, as well as the advertisers in our Journal. The Eastern Cape Branch, and in particular their Chairperson, Werner Illenberger, assisted by members of other NACA branches and by Colleen Durant and Maverick Enterprises, deserve a special mention for the workshop and conference that they have organized for us this year. They have ably continued the excellent trend established for NACA conferences and have set a challenge for future Annual Conference organizers.

\section{Concluding remark and handover to in-coming President}

Tonight my term of office as NACA President comes to an end. I thank you, the members of NACA for allowing me the privilege of having been your President. I hand over to Ms Yvonne Scorgie who I am confident will, together with the new Vice President, Mr Greg Scott, take clean air and NACA to new heights, enhancing the visibility of both our Association and the air we breathe.

Thank you.

Tony Stott

19 October 2006 